\title{
Método experimental, educação e arte: uma reflexão sobre a concepção de democracia de Dewey
}

Experimental method, education and art: a thought on Dewey's conception of democracy

Método experimental, educación y arte: una reflexión sobre la concepción de democracia de Dewey

\section{Karina dos Santos de Moura Buzin ${ }^{1}$ Aparecida Favoreto ${ }^{2}$}

\footnotetext{
1 Bolsista no Programa de Pós-Graduação Stricto Sensu Mestrado em Educação, na linha de História de Educação da Universidade Estadual do Oeste do Paraná. Possui Especialização Lato Sensu em Educação (2019) e em Educação Infantil (2018). Graduação em Pedagogia (2018). Tem experiência na área de Educação, com ênfase em História da Educação, atuando principalmente nos seguintes temas: Intelectuais da Educação, John Dewey, História da Educação

2 Docente Associada da Universidade Estadual do Oeste do Paraná; Professora e Pesquisadora no Mestrado e Doutorado em Educação e no Colegiado de Pedagogia da UNIOESTE - Cascavel, PR. Membro e líder do Grupo de Pesquisa História e Historiografia na Educação (UNIOESTE/CNPq).

Doutorado em Educação pela Universidade Federal do Paraná; Mestrado em Educação pela Universidade Estadual de Maringá; Especialização em Fundamentos da Educação pela Universidade Estadual de Maringá; Graduação em História pela Universidade Estadual de Maringá.

Lattes: http://lattes.cnpq.br/3103506424875004

ORCID iD https://orcid.org/0000-0003-3883-5604
} 


\section{RESUMO}

Nas discussões relacionadas aos conceitos de arte e de educação na escola, destaca-se a teoria de John Dewey. Este pensador contribuiu com o debate a partir das suas perspectivas históricas e sociais. Este artigo tem como objetivo rememorar as reflexões expostas por Dewey sobre os conceitos de arte, de educação, de método experimental e da pedagogia para o desenvolvimento da democracia. Assim, são estabelecidas relações qualitativas dos conceitos com o ideal democrático defendido pelo autor. Também busca pensar sua teoria e sua defesa de uma formação reflexiva em relação ao contexto histórico-social. Por fim, destaca que a perspectiva educacional de Dewey se entranha a sua análise da sociedade. Neste aspecto, o intelectual ideou preparar o indivíduo para uma sociedade em mudança constante, de modo a contribuir com a construção da democracia, porém, limitou-se à perspectiva do desenvolvimento da sociedade burguesa.

\section{PALAVRAS-CHAVE}

John Dewey; Arte; Educação; Democracia; Método Experimental.

\section{ABSTRACT}

In discussions related to the concepts of art and education at school, one can highlight John Dewey's theory. This thinker has contributed to the debate starting from his historical and social perspectives. This article aims to recollect the exposed reflections of Dewey on the concepts of art, education, experimental method and pedagogy for the development of democracy. Thus, qualitative relationships between these concepts and the democratic ideal defended by the author are established. This work also seeks to think through his theory and his defense of a reflexive formation in relation to a social historical context. Finally, it stands out that Dewey's educational perspective gets in the way of his society analysis. In this aspect, the intellectual idealized to prepare the individual for a society in constant change, in order to contribute to the construction of democracy, however, he limited himself to the perspective of the development of bourgeois society.

\section{KEY WORDS}

John Dewey; Art; Education; Democracy; Experimental Method. 


\section{RESUMEN}

En las discusiones relacionadas con los conceptos de arte y educación en la escuela, se destaca la teoría de John Dewey. Este pensador contribuyó al debate desde su perspectiva histórica y social. Este artículo tiene como objetivo recordar las reflexiones expuestas por Dewey sobre los conceptos de arte, educación, método experimental y pedagogía para el desarrollo de la democracia. Así, se establecen relaciones cualitativas entre los conceptos y el ideal democrático defendido por el autor. También busca reflexionar sobre su teoría y su defensa de una formación reflexiva en relación al contexto histórico-social. Finalmente, destaca que la perspectiva educativa de Dewey es parte de su análisis de la sociedad. En este aspecto, el intelectual pretendía preparar al individuo para una sociedad en constante cambio, a fin de contribuir a la construcción de la democracia, sin embargo, se limitó a la perspectiva del desarrollo de la sociedad burguesa.

\section{PALABRAS CLAVE}

John Dewey; Arte; Educación; Democracia; Método Experimental. 


\section{Introdução}

A discussão sobre a arte e a educação tem estado em voga atualmente, principalmente depois da nova $\mathrm{BNCC}^{1}$. Em parte, o debate discute a carga horária, mas também traz importantes reflexões sobre a definição da arte e sua contribuição na formação escolar.

Entretanto, esse debate não é exclusivo da atualidade. Diversos teóricos já se debruçaram sobre o tema, entre os quais merece destaque John Dewey (1859 a 1952) 2. Este autor, além de uma grande produção teórica, a qual incidiu em discussões educacionais em quase todos os continentes, trouxe contribuições extraordinárias para a pedagogia e, inclusive, influenciou consideravelmente o debate sobre a constituição do sistema escolar no Brasil ${ }^{3}$.

Sobre Dewey, chama atenção sua unidade reflexiva e como ele compreendia a relação entre o método pedagógico e o processo de constituição da democracia burguesa. No que se refere a arte, inúmeras vezes se referiu à questão. Em 1934 publicou o livro Arte como experiência; nessa obra, seguindo os pressupostos da pedagogia experimental, destacou a arte como comunicação de experiências estéticas e um elemento de integração social do homem com o mundo. Entretanto, mesmo diante do grande legado educacional deixado por Dewey, sua produção recebeu muitas críticas e/ou repetições inadvertidas, o que torna necessária a retomada da análise de suas reflexões.

Diante disso, este artigo, a partir de uma pesquisa bibliográfica, objetiva recuperar suas contribuições. No entanto, longe de traçar uma defesa ou crítica, busca-se pensar o significado de sua teoria em relação ao contexto, focando no debate sobre a relação entre arte, educação e democracia. Para tanto, ao se destacar alguns argumentos do teórico, pontua-se alguns fatos históricos que marcaram o período. Por fim, espera-se traçar algumas reflexões que possam contribuir com a formação de professores, não só para resgatar o pensamento de Dewey, mas também no sentido de apontar como o debate sobre as metodologias ressaltam concepções sociais.

\section{Educação e experiência}

Dewey viveu nos Estados Unidos da América, em uma época em que a sociedade passou por diversas mudanças, que influenciaram o modo de vida e as perspectivas educacionais do filósofo. Nesse sentido, concorda-se com Souza e Galter (2018, p.

\footnotetext{
1 A Base Nacional Comum Curricular (BNCC) é um documento que normatiza a educação básica, estabelecendo aprendizagens essenciais para os alunos. Em 2017 foi publicado a nova Base para a Educação Infantil e Ensino Fundamental e em 2018, para o Ensino Médio.

2 Filósofo estadunidense, influenciado pela teoria de Kant e Darwin, é considerado um dos fundadores do pragmatismo. Aplicou sua teoria educacional em um laboratório em Chicago. Dedicou-se em toda a sua vida às causas progressistas, lutando pelo direito de participação democrática das minorias. Ver mais em: Buzin, (2021).

3 Sobre esta questão, cita-se: Favoreto (1998); Souza e Martineli (2009), entre outros.
} 
163), quando afirmam que "[...] a teoria deweyana certamente está entranhada na sua leitura de mundo que, em seu contexto histórico, presenciava muitas transformações de ordem econômica, política, cultural e social".

Naquele contexto, diante do movimento imigratório, dos reflexos da Guerra Civil Americana, do clima gerado diante de duas Guerras mundiais, da Revolução Soviética, da crise de 1929, da industrialização e do avanço tecnológico e científico, a escola foi defendida como um elemento social. Considerou-se que ela poderia contribuir com a formação do trabalhador e do cidadão, contribuindo com o ensino dos conhecimentos necessários à nova era produtiva. A instituição escolar também foi defendida no sentido de colaborar com a unidade nacional e a efetivação da democracia.

Dewey, pesquisador e educador, atuou em defesa da escola pública e de uma nova pedagogia. Ele acreditava que o método educacional teria potencial para desenvolver novas atitudes mentais, por meio das quais o aluno não só teria acesso a um vasto conhecimento da ciência e da sociedade, mas também tornar-seia mais perspicaz, ativo, autônomo e responsável socialmente. Desse modo, estaria preparado para os desafios da sociedade moderna, a qual, cada vez mais, passava constantemente por mudanças. Para o intelectual, por intermédio da educação, poder-se-ia mudar a forma de pensar. E consequentemente, promover a inteligência, a conexão entre o pensar, o planejar e o fazer, bem como a integração nacional ao progresso social.

Nesse objetivo, ele traçou severas críticas ao modelo de educação da época, o qual denominava como tradicional. Para o filósofo, o modelo de ensino priorizava a repetição de conteúdos estanques e distantes da vida prática do aluno, o que não despertava seu interesse e nada significava para a solução de seus problemas diários. Em contraposição ao modelo tradicional, o pensador defendeu o método experimental no ensino escolar ${ }^{4}$.

Para Dewey, a experiência seria parte da vida do homem e possuiria valores qualitativos diversos, com a possibilidade de resultar em desenvolvimento intelectual, desde que obtivessem qualidade educativa e se fizessem em relação ao pensamento reflexivo. Afirmando haver duas espécies de experiências (não reflexiva e reflexiva), asseverou que no ensino, a experiencia deveria ser reflexiva. Desse modo, a atividade educacional precisaria ser organizada e orientada pelo professor, buscando despertar o interesse e o esforço intelectual do aluno e o conduzindo a "descobrir as relações específicas entre uma coisa que fazemos e a consequência que resulta", tornando "explicito o elemento inteligível", bem como o fim em vista das experiências (DEWEY, 1979a, p. 159. Grifos do autor).

Segundo Dewey, "toda experiência deveria contribuir para o preparo da pessoa em experiências posteriores de qualidade mais ampla ou mais profunda. Isto é o próprio sentido de crescimento, continuidade, reconstrução da experiência" (DEWEY,

4 Para Dewey (1979a, p. 190-191, grifo do autor), o método pedagógico experimental se caracterizaria pelos seguintes atos: "o problema, a coleta e a análise de dados, o planejar e a elaboração de sugestões ou ideias, a aplicação experimental e o ato de pôr em prova, e a conclusão ou juízos resultantes" 
1979b, p. 41). Então, a experiência que não ampliasse a capacidade do educando de estabelecer relações entre conhecimento, coisas e ações e que não propiciasse sequência aos esforços, não seria válida para o ensino. Ou seja, para o intelectual, experiência "significa uma troca ativa e alerta com o mundo; em seu auge, significa uma interpenetração completa entre o eu e o mundo dos objetos e acontecimentos" (DEWEY, 2010, p. 83). Logo em seguida, ainda complementou relatando que "a experiência é o resultado, o sinal e a recompensa da interação entre organismo e meio que, quando plenamente realizada, é uma transformação da interação em participação e comunicação" (DEWEY, 2010, p. 88-9).

Assim, em matéria de educação, esta deveria proporcionar um exercício reflexivo contínuo, atribuindo nova qualidade à capacidade de pensar situações. Então, não se trataria da simples experiência imediata e limitada ao agir mecânico do cotidiano industrial. Mesmo que ela fosse necessária, para ser educativa, deveria ter relação com o pensamento reflexivo, o qual seria desenvolvido a partir dos conhecimentos científicos. Neste papel, a educação escolar seria imprescindível. De tal modo, Dewey (1979a, p. 08) escreveu:

\begin{abstract}
Sem essa educação formal é impossível a transmissão de todos os recursos e conquistas de uma sociedade complexa. Ela abre, além disso, caminho a uma espécie de experiência que não seria acessível aos mais novos, se estes tivessem de aprender associando-se livremente com outras pessoas, desde que livros e símbolos do conhecimento têm que ser aprendidos.
\end{abstract}

Em defesa da escola, o intelectual destacou que os conhecimentos conquistados pela humanidade no decorrer da sua história eram necessários para o progresso intelectual dos indivíduos e da sociedade. Também afirmou que o homem sem educação escolar tenderia a se limitar ao que lhe é comum e agradável, restringindo seu conhecimento ao do seu grupo social e/ou da comunidade em que vive. Por outro lado, analisando as características do trabalho industrial, sua complexidade, a divisão do trabalho e da sociedade, ele destacou que era necessário promover a integração, pois, sem ela, correr-se-ia o risco de impossibilitar o desenvolvimento da sociedade. Para o filósofo:

A eficiência da produção exige, com frequência a divisão do trabalho. Mas este se reduzirá a uma rotina maquinal se o trabalhador não vir as relações técnicas, intelectuais e sociais encerradas naquilo que está fazendo, em relação às demais partes do trabalho, e não se dedicar a seu trabalho por essa compreensão (DEWEY, 1979a, p. 91).

Para se opor a situação de opressão e de distanciamento criada pelo contexto da divisão do trabalho, Dewey (1956) defendeu uma mudança pedagógica. Nesse quesito, preocupou-se em idealizar uma escola que formasse a todos.

[...] diante do distanciamento da inteligência do trabalhador com o seu fazer, defende que o sistema educativo deveria buscar formas de superar o ponto de vista unilateral predominante, principalmente, entre aqueles que 
determinam os fins sociais [...] É importante mencionar que, para Dewey, os danos provocados pela visão unilateral não se restringiriam apenas à classe trabalhadora, mas atingiriam também a classe com maior poder aquisitivo, cujos danos se apresentariam, principalmente, na cultura (GALTER; FAVORETO, 2020, p. 7).

Para Dewey, o ensino escolar era indispensável, pois poderia reestabelecer significado às coisas. No entanto, o professor, sendo conhecedor dos conteúdos especializados, da sociedade e da psicologia, deveria conduzir o ensino, despertando o interesse da criança para solucionar os problemas - individuais e sociais -. $\bigcirc$ conteúdo escolar, na forma de situações sociais, assumiria significação educativa por intermédio de um processo investigativo organizado e dirigido pelo professor. E assim, com o conteúdo, representando situações reais de problemas, provocaria o grupo de alunos a interpretar os dados, examinar as relações, levantar hipóteses e verificar a extensão e consequências das decisões tomadas.

Pressupondo que o método experimental possibilitaria formar novos hábitos de pensar, Dewey (1979a, p. 150) acreditava que as pessoas, cujas inteligências fossem "exercitadas ao contato com as coisas e fatos, em ocupações ativas com finalidades (seja no jogo, seja no trabalho)", se dedicariam com mais interesse e disciplina à observação, à aquisição de conhecimentos informativos e ao uso de uma imaginação construtora, o que poderia contribuir para com o progresso social. Nesse aspecto, o método pedagógico seria essencial, pois, aliado ao conhecimento, tornaria inteligível as experiências sociais, formando alunos preparados para participarem ativamente na solução dos problemas diários e das decisões coletivas. Nessa perspectiva, ele concebe que o homem

[...] adquire conhecimento a partir da investigação inteligente desenvolvida no processo da experiência. O fundamento do conhecimento seria, portanto, a experiência aliada à reflexão metódica, uma vez que seria por intermédio dela que o homem conhece a si próprio e o mundo natural e social que o circunda (GALTER; FAVORETO, 2020, p. 3-4).

Pressupondo que a experiência é uma forma de intercâmbio entre o indivíduo e o seu meio, Dewey propôs uma reorganização da educação. Para ele, por meio do método experimental seria possível efetuar a conjunção entre conhecimento, fazer, consequência, interesse, disciplina, esforço e continuidade, formando indivíduos autônomos e responsáveis socialmente.

Dewey pontuou que a experiência conduzida inteligentemente seria um fator significativo no desenvolvimento da aprendizagem. Com base neste pressuposto, ao se referir a arte, pontuou que ela seria importante, pois poderia favorecer a aproximação entre o pensar e o fazer. Para ele, estando a arte presente no fazer humano, ela traz em seu bojo a observação, a imaginação e a necessidade da resolução de problemas, na mesma medida em que contém qualidade estética integrada ao saber individual e ao meio social, tudo isso, poderia implicar em um novo hábito de pensar. 


\section{A arte enquanto unidade da experiência}

Em sua obra Arte como experiência, Dewey, observando os reflexos negativos da divisão de classes e do trabalho, afirmou haver um distanciamento entre a ação e o pensamento, assim como um afastamento entre a arte e a vida social. Na sociedade moderna, o artista, sem condições de acompanhar a produção mecanizada em massa, distanciou a sua arte da experiência social. "Por conseguinte, os produtos artísticos assumem em grau ainda maior a aparência de algo independente e esotérico" (DEWEY, 2010, p. 69).

Contrapondo-se a essa visão de arte, Dewey (2010, p. 127) afirmou que ela "denota um processo de fazer ou criar", por meio do qual a obra seria o produto final. Sobre esse processo, asseverou que o artista necessitaria possuir percepção e controle, o que exigiria um conjunto de conhecimentos e acúmulo de experiências, bem como planejamento, atenção e capacidade de estabelecer relação entre o que faz, o que já fez e o que fará em seguida. Segundo Dewey (1956, p. 63), é na interação entre o fazer, a inteligência e as vivências, que o conhecimento técnico dominado pelo artista "mescla-se com pensamento e sentimento". Então, arte seria a deliberação consciente de uma ação que se utiliza das coisas encontradas. Para o intelectual, de modo consciente, o homem "converte as relações de causa e efeito encontradas na natureza em relações de meios e consequência" (2010, p. 92). Nessa ação consciente, por intermédio da arte, o homem amplia a própria vida, visto que produz significados e "prefigura-se nos próprios processos do viver" (DEWEY, 2010, p. 92).

Com base nesses pressupostos, Dewey pontuou que a arte poderia estabelecer uma aproximação entre a teoria e a prática. Igualmente, se opôs ao caráter elitista da sociedade em torno da arte e à ideia de que o lugar apropriado para ela seria o museu. No mesmo sentido, se posicionou de forma crítica ao caráter comercial que a envolvia. Assim, para o filósofo, a arte não se caracterizava por um conhecimento apurado de técnicas e/ou de personalidades e singularidades, mas se tratava de um reconhecimento da inseparabilidade ou continuidade da sociedade, do homem e da natureza. Nesse aspecto, ao se observar as experiências passadas e as atitudes do artista registradas na arte, poder-se-ia refletir sobre a própria vida.

A respeito das obras de arte, Dewey (2010, p. 59) afirmou que eram "produtos dotados de existência externa e física". Mas também eram mais do que matérias, pois correspondiam a uma forma de comunicação de experiências.

Apoiando-se nessa tese, ou seja, de comunicação de experiências, Dewey destacou que a arte não seria apenas uma expressão individual, nem somente teria um valor intelectual, mas representava as experiências significativas, instigando contínuas reflexões sobre o homem e o mundo. Segundo o filósofo (2010, p. 128), "a arte, em sua forma, une a mesma relação entre o agir e o sofrer, entre a energia de saída e a de entrada, que faz que uma experiência seja uma experiência". Para o pensador:

Ver, perceber, é mais do que reconhecer. Não identifica algo presente em termos de um passado desvinculado dele mesmo. $O$ passado se transpõe 
para o presente, expandindo e aprofundando o conteúdo deste último. Aí se ilustra a tradução da pura continuidade do tempo externo para a ordem e organização vitais da experiência (DEWEY, 2010, p. 91).

$\mathrm{Na}$ interação entre o passado e o presente, a arte se caracterizaria por ser "um ato de reconstrução, e a consciência torna-se nova e viva" (DEWEY, 2010, p. 135). Ou seja, numa dupla relação, primeiramente, a arte seria entendida como interação entre o homem e o meio e quando trazida ao seu esplendor, a interação seria permeada também pela comunicação de experiências.

Nesse sentido, Montenegro Ortíz (2014), ao analisar a concepção de arte e de experiência estética em Dewey, afirma que ele pressupunha que a arte tem uma qualidade estética, a qual, relacionada a sentimento, imaginação, capacidade cognitiva e critério consciente ou inconsciente para discernir o que é ou não belo, daria consistência ao conceito de experiência estética. Nesse caso, a experiência com a arte congregaria valores, harmonia, equilíbrio, estética, inteligências e intenção diretiva, na mesma medida em que possibilitaria vivenciar as relações do homem com a natureza e do homem com o meio, associando-se à atividade humana. Desse modo, a arte no conceito deweyano tratava-se da consumação de uma experiência estética perceptiva. Se a obra de arte seria algo exterior, a estética seria a "experiência como apreciação, percepção e deleite. Mais denota o ponto de vista do consumidor do que o do produtor" (DEWEY, 2010, p. 127).

Pressupondo a arte como comunicadora de experiências e integradora de conhecimentos, hábitos, técnicas e finalidades, o teórico norte-americano afirmou que ela deveria ser considerada em dois processos, o de criação e o de apreciação.

[...] tanto é um produto, quanto o próprio processo de execução, de modo que $\mathrm{o}$ artista simultaneamente 'faz e padece' a própria obra. A criação artística, de acordo com Dewey, é um processo empático, pois o artista se coloca no lugar do apreciador, precisa simultaneamente produzir e antecipar a recepção (FONSECA; TOSTA, 2019, p. 248, grifo dos autores)

Sendo a produção artística expressão das experiências do artista, produz significados para um ser que a apreciará. Desse modo, a qualidade da experiência estaria na qualidade das relações estabelecidas, ou seja, na comunicação entre o produtor e o observador e entre a arte e a vida. Assim, "uma obra somente é considerada artística se entrar em um fluxo interacional no qual determinadas qualidades são valorizadas como tal e compartilhadas" (FONSECA; TOSTA, 2019, p. 249). Em um processo de interação, se por um lado, o artista deveria continuamente controlar suas ações conforme a produção desejada, por outro, deveria incorporar uma posição de espectador. Nas palavras de Dewey,

O fazer ou o criar é artístico quando o resultado percebido é de tal natureza que suas qualidades, tal como percebidas, controlam a questão da produção. $\mathrm{O}$ ato de produzir, quando norteado pela intenção de criar algo que seja desfrutado na experiência imediata da percepção, tem qualidades que faltam à atividade espontânea ou não controlada. $\mathrm{O}$ artista, ao trabalhar, incorpora 
em si a atitude do espectador (2010, p. 128).

E assim, "em uma enfática experiência artístico-estética, a relação é tão estreita que controla ao mesmo tempo o fazer e a percepção" (DEWEY, 2010, p. 130). De tal modo, o ato perceptivo envolve a compreensão da relação intrínseca entre meio e objeto, arte e experiência, produto, produtor e apreciador. "Para perceber, o espectador ou observador tem de criar sua experiência" (DEWEY, 2010, p. 137). Para Dewey, toda e qualquer atividade para ser verdadeiramente significativa deveria ocorrer na e a partir da experiência reflexiva. E, no que se refere a arte, salientou ser necessário "recuperar a continuidade da experiência estética com os processos normais do viver" (DEWEY, 2010).

Munido de uma visão crítica sobre a perspectiva espiritual, transcendental ou simplesmente prática da arte, Dewey teorizou sobre o valor fundamental dos meios internos e externos da atividade do homem. Assim, defendeu que "a arte não é puramente interior, nem puramente exterior; nem meramente mental, nem simplesmente material. Mas, como qualquer outra espécie de atividade, ela produz mudanças no mundo" (DEWEY, 1979a, p.148). Porém, não se referia a mudanças mecânicas, mas, se tratando de comunicação de experiências, em contato com coisas e fatos, a arte poderia despertar novas atitudes, tais como a disciplina, o interesse e a força de vontade. Pela participação, também poderia alargar as mentes em ocupações com finalidades previstas, integrando o conhecer, a ação e o indivíduo ao meio e ao social. Nesse aspecto, a arte poderia desenvolver "a observação, a aquisição de conhecimentos informativos e o uso da imaginação construtora" (DEWEY, 1979, p. 150).

Sobre tais perspectivas, Pereira; Martins; Alves e Delgado (2009, p. 160) ao analisarem o ideal educacional de Dewey, escrevem que ele valorizava as atividades manuais, visto que:

[...] as mesmas apresentam situações problemas concretas para serem resolvidas. E além do mais desenvolve o espírito de se trabalhar em equipe, pois através da divisão das tarefas entre os participantes, se estimula a cooperação e consequentemente se desenvolve um espírito social. Para Dewey a iniciativa e a independência levam à autonomia que na realidade são virtudes de uma sociedade realmente democrática, ao contrário do ensino tradicional que valoriza e preza pela obediência (PEREIRA; MARTINS; ALVES e DELGADO, 2009).

Sobre a relação entre as artes e a formação, com base em Freitas (2009, p. 51) é possível afirmar que em Dewey:

[...] a preocupação com as artes, a música, o teatro, a pintura, etc., está comprometida com as bases culturais da democracia, inclusive, como uma forma de se combater o totalitarismo, revelando uma perspectiva de integração social e, portanto, de sua concepção de Educação Integral (FREITAS, 2009, p. 51). 
Dewey reconhecia a importância da experiência no processo educativo. Pensava a arte como comunicação de experiências e integração entre as experiências do executor e do observador. Deste modo, considerava que a arte poderia contribuir com o desenvolvimento do pensamento reflexivo, da autonomia, do espírito participativo e da responsabilidade social. Qualidades que pressupunha serem essenciais para o desenvolvimento da democracia.

\title{
O ideal democrático na teoria deweyana
}

Dewey compreendia que a sociedade seria melhor se os indivíduos fossem integrados à vivência social. Para tanto, todos deveriam participar ativamente da solução dos problemas coletivos. Assim, a democracia não se resumia ao direito de manifestar opiniões e/ou ao direito a voto, pois, se não houvesse participação do indivíduo, a organização democrática não se efetivaria.

Para o intelectual norte-americano, essa ação poderia influenciar no desenvolvimento da comunidade, contribuindo com o progresso particular e social.

\begin{abstract}
Noutros termos, para Dewey (1916/1979, p. 93), a democracia é mais que uma forma de governo e/ou sufrágio popular, ela é 'primacialmente uma forma de vida associada, de experiência conjunta e mutuamente comunicada'. O autor entende que a democracia ocorreria pela relação entre os interesses diversos e mutuamente comunicados. Desta forma, cada ação social e/ou atividade profissional deveria ter seus interesses voltados para a sociedade, ampliando a capacidade individual de assumir responsabilidades pelo bem-estar social dos homens (GALTER; FAVORETO, 2020, p. 8).
\end{abstract}

Neste sentido, o ensino deveria ser organizado de modo que pudesse propiciar experiências participativas e desenvolver o interesse para as questões sociais no indivíduo, bem como, a sua responsabilidade com os ideais coletivos.

\footnotetext{
Os objetivos educacionais de Dewey eram incutir o caráter democrático em todas as esferas sociais, desenvolver a colaboração e a mútua responsabilidade social entre indivíduos livres e cientificamente mais inteligentes na busca por soluções mais fecundas aos problemas humanos (GALTER; FAVORETO, 2020, p. 12).
}

Consciente das divisões da sociedade industrial, das mazelas sociais e dos limites da democracia burguesa, Dewey apontou que a pedagogia experimental poderia integrar o ensino intelectual e moral à formação de novos hábitos, os quais seriam essenciais para a democracia. Em meio a uma sociedade em constantes mudanças, permeada por um clima de guerra e ao mesmo tempo dependente socialmente, o intelectual acreditava que era necessário estabelecer um equilíbrio entre a produção em massa, produção individual, organização política e os interesses particulares. Dessa forma, acreditava que associando esforço deliberado, capacidade reflexiva, 
observação, interesse, disciplina, responsabilidade, autonomia e a coparticipação, a democracia poderia se efetivar.

Para o filósofo estadunidense, a democracia seria a forma mais inteligente de se organizar e viver em sociedade. Porém, todas as pessoas deveriam ter a oportunidade de atuar nos grupos sociais em condições iguais. Neste pensamento, por intermédio das mútuas experiências individuais compartilhadas, todos deveriam se apropriar dos conhecimentos e da cultura existente. Para Dewey, por meio da pedagogia experimental, da ciência, da arte e do desenvolvimento de hábitos de reflexão, poderse-ia construir uma vivência mais harmoniosa, inteligente e democrática.

Desse modo, ao priorizar o aspecto pedagógico, Dewey limitou os problemas referentes a democracia burguesa à questão cultural, secundarizando o debate sobre os movimentos políticos e a organização do Estado. Nesse sentido, com base em Nascimento e Favoreto (2018, p. 261), destaca-se que o progresso social idealizado por Dewey não implicava "um rompimento com as estruturas do capital, mas a preparação dos indivíduos para participar e usufruir da riqueza material e cultural da sociedade". Em outros termos, as ideias de progresso e de democracia em Dewey limitavam-se a continuidade dos princípios burgueses, sendo a educação um importante fator para produzir indivíduos integrados ao social.

Neste aspecto, pode-se afirmar que a teoria de Dewey se traduz numa perspectiva progressiva da história. ${ }^{5} \bigcirc$ autor acreditava que a pedagogia, pela experiência, formaria os cidadãos integrados à sociedade que estava em constante mudança devido a produção industrial, desenvolvimento tecnológico e complexidades da vida social.

\section{Considerações finais}

Por meio da pesquisa bibliográfica, se observou que Dewey, vivendo em um contexto marcado pelo desenvolvimento industrial, mudanças e crises sociais, defendeu uma ampla reforma escolar. Para o filósofo, diante dos problemas, conflitos e do divórcio entre a teoria e a prática, seria necessária uma mudança pedagógica. Nesse sentido, defendeu a pedagogia experimental, a qual acreditava que, aliada à ciência e à arte, poderia desenvolver o pensamento reflexivo, o interesse, a disciplina, o esforço, a autonomia, a coparticipação e a responsabilidade social; hábitos que, segundo o intelectual, eram essenciais para que todos tivessem acesso aos bens culturais e econômicos para que a democracia pudesse ser efetivada.

No que se refere à arte, entendendo-a como comunicação de experiências estéticas, Dewey pontuou que ela poderia proporcionar uma maior aproximação entre o pensar e o fazer, bem como entre o conhecimento, o objeto, a prática e os objetivos finais. Como comunicação de experiências, a arte poderia desenvolver o

5 Sobre as diferentes perspectivas de transformação social, consultar: Favoreto e Galter (2020) e Klein, Favoreto e Figueiredo (2014). 
domínio consciente da ciência, na medida em que desenvolveria a curiosidade, a atitude investigativa, a coparticipação e o conhecimento sobre a relação entre a ação humana, as consequências e a finalidade. Isso, para além da maior compreensão da relação do indivíduo com o mundo, desenvolveria a responsabilidade social.

Nesse caso, a compreensão dos elementos norteadores da produção artística se constituiria em relação às expressões do artista enquanto um ser produtivo, que elabora sua obra a partir de uma ação intelectual, por meio das interações entre meio, instrumentos e a significação que deseja expressar ao apreciador de sua arte. Assim, ela seria capaz de construir significados. Noutros aspectos, acreditava que a arte, ao proporcionar comunicação entre experiências, daria novo significado ao conhecimento e ao ato de pensar, desenvolvendo assim, o hábito do pensamento reflexivo.

No entanto, se ele desejava mudar o hábito de pensar por intermédio da educação, acreditando que por este viés tonaria os indivíduos mais reflexivos e participativos na sociedade, esta perspectiva não presumia romper com a ordem social burguesa. Para Dewey, em uma ordem progressiva, a sociedade burguesa poderia ter seus problemas sociais resolvidos, por intermédio da educação. No caso, a pedagogia experimental contribuiria para formar indivíduos mais conscientes e mais ativos socialmente, contribuindo para construir uma democracia de fato. Deste modo, seu ideal educacional focava mais na mudança da forma de pensar dos indivíduos.

Se os pressupostos de Dewey estão certos ou errados, dificilmente será possível responder com segurança. Mas, retomar ao seu pensamento educacional, verificar como ele pensa a relação entre a arte, a educação, a pedagogia experimental e a democracia, nos ajuda a pensar sobre o debate atual sobre o ensino e a sociedade.

\section{Referências}

BRASIL. Base Nacional Comum Curricular: Fundamentos Pedagógicos e Estrutura Geral da BNCC: versão 3, Brasília, 2017.

BRASIL. Base Nacional Comum Curricular: Ensino Médio. Brasília: MEC/Secretaria de Educação Básica, 2018.

BUZIN, Karina dos Santos de Moura. Interesse e esforço: uma análise histórica a partir da teoria de John Dewey (1859-1952). 2021. 128 f. Dissertação (Mestrado em Educação). Programa de Pós-Graduação em Educação. Universidade Estadual do Oeste do Paraná UNIOESTE, Cascavel, 2021.

DEWEY, John. A natureza humana e a conduta. Bauru, SP: Tipografias e livrarias Brasil S/A, 1956.

DEWEY, John. Arte como experiência. Tradução Vera Ribeiro. São Paulo: Martins, 2010. 
DEWEY, John. Democracia e educação: introdução à filosofia da educação. 4.ed. Tradução de Godofredo Rangel e Anísio Teixeira. São Paulo: Ed. Nacional, 1979a.

DEWEY, John. Experiência e educação. Tradução de Anísio Teixeira. 3.ed. São Paulo: Ed. Nacional, 1979b.

FAVORETO, Aparecida. Uma análise histórica da concepção de progresso no projeto educacional de Anísio Teixeira. 1998. Dissertação (Mestrado em Fundamentos da Educação) - Universidade Estadual de Maringá, Maringá, PR, 1998.

FAVORETO, Aparecida. GALTER, Maria Inalva. Teorias da transformação social: positivismo x marxismo, 2020. Revista Educere Et Educare, Vol. 15, N.34, jan./mar. 2020. Ahead of Print. DOI: 10.17648/educare.v15i34.23312 Disponível em: http://e-revista.unioeste.br/index.php/ educereeteducare/article/view/23312/15674. Acesso em: 04 jun. 2021.

FONSECA, Cláudia Chaves. TOSTA, Sandra Pereira. Comunicação, arte e educação em John Dewey. Revista Linhas. Florianópolis, v. 20, n. 42, p. 238-254, jan./abr. 2019. Disponível em: http://dx.doi.org/10.5965/1984723820422019238. Acesso em: 04 jun. 2021.

FREITAS, Cezar Ricardo de. O escolanovismo e a pedagogia socialista na união soviética no início do século XX e as concepções de educação integral e integrada. 2009. Dissertação (Mestrado em Educação) - Universidade Estadual do Oeste do Paraná, Cascavel, 2009.

GALTER, Maria Inalva; FAVORETO, Aparecida. John Dewey: um clássico da educação para a democracia. Linhas Críticas, Brasília, DF, v. 26, 2020. Disponível em: https://periodicos.unb. br/index.php/linhascriticas/article/view/28281. Acesso em: 01 out. 2020.

KLEIN, Ligia Regina. FAVORETO, Aparecida. FIGUEIREDO, Ireni Marilene Zago. Processo de transformação e Conservação social: uma reflexão a partir da Fábula dos Porcos Assados. Revista Teoria e Prática: UEM, 2014. Disponível: http://periodicos.uem.br/ojs/index.php/ TeorPratEduc/article/view/25464. Acesso em: 4 jun. 2021.

MONTENEGRO ORTíZ, Carlos. Arte y experiencia estética: John Dewey. REVISTA NODO, [S. I.], v. 9, n. 17, p. 95 - 105, 2014. Disponível em: http://revistas.uan.edu.co/index.php/nodo/ article/view/620. Acesso em: 4 jun. 2021.

NASCIMENTO, Lorivaldo do. FAVORETO, Aparecida. Émile Durkheim, John Dewey e Antônio Gramsci. Revista Educação Em Questão, 56 (49), 2018. https://doi.org/10.21680/19811802.2018v56n49ID14010. Acesso em: 4 jun. 2021.

PEREIRA, Eliana Alves; MARTINS, Jackeline Ribeiro; ALVES, Vilmar dos Santos; DELGADO, Evaldo Inácio. - A contribuição de John Dewey para a Educação. Revista Eletrônica de Educação. São Carlos, SP: UFSCar, v.3, no. 1, p. 154-161, mai. 2009. Disponível em http:// www.reveduc.ufscar.br/index.php/reveduc/article/view/38/37 Acesso em 04 jun. 2021.

SOUZA, Helton Adriano de; GALTER, Maria Inalva. A educação e a transformação social nos clássicos: Karl Marx, Émile Durkheim e John Dewey. EDUCERE - Revista da Educação, 


\section{Revista Apotheke}

Umuarama, v. 18, n. 1, p. 147-164, jan./jun. 2018.

SOUZA, Rodrigo Augusto de; MARTINELI, Telma Adriana Pacífico. Considerações históricas sobre a influência de John Dewey no pensamento pedagógico brasileiro. Revista HISTEDBR On-line, Campinas, n. 35, p. 160-162, set. 2009. Disponível em: https://periodicos.sbu. unicamp.br/ojs/index.php/histedbr/article/view/8639620. Acesso em: 03 fev. 2020.

Submissão: $26 / 06 / 21$

Aceitação: 31/08/21 